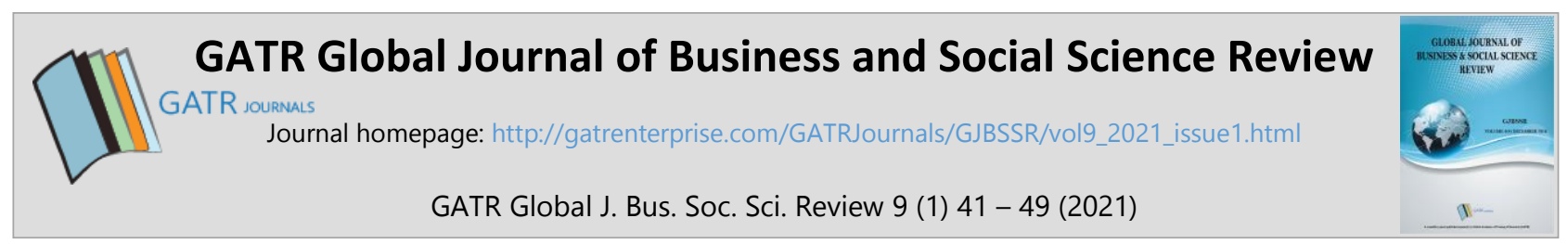

\title{
The effects of loyalty, Satisfaction, and motivation on student's performance: A study of higher education in South Africa
}

\author{
Elizabeth Chinomona $^{1 *}$, Marie Brinda Bikissa-Macongue ${ }^{2}$ \\ Vaal University of technology, P Bag X021, 1900, Vanderbijlpark, South Africa
}

\begin{abstract}
Objective - Worldwide, higher education is critical for the social economic development of the society. However African countries such as South Africa, fail to produce quality graduates capable of facing the challenges of the fourth industrial revolution. Considering the increasingly competitive and dynamic environment, African countries can no longer ignore the needs and factors required to enhance student performance. The aim of this research is to examine the influence of student motivation, satisfaction and loyalty on the student performance of higher education in South Africa.

Methodology/Technique - A quantitative approach was adopted in which a questionnaire was used to collect data from 400 students and 335 was usable yielding a valid response rate of $84 \%$. The data was analyzed with the aid of 2 software programs namely, statistical package for social science (SPSS 25.0) and analysis of moment structures (AMOS 25.0). In addition, confirmatory factors analysis (CFA) and structural equation modelling (SEM) were used to test the relationship between constructs and development of the hypotheses.

Finding and Novelty - The current findings reveal that students who are motivated, satisfied and loyal to their institution are more likely to perform better than those who are not. The results also reveal that there is a significant relationship between student satisfaction and student performance. It was also shown that the higher the level of satisfaction, loyalty and motivation, the better the performance. Therefore, it is recommended that universities or institutions develop an environment that promote satisfaction, loyalty and motivation of their students.
\end{abstract}

Type of Paper: Empirical.

JEL Classification: $121,128$.

Keywords: Student Motivation; Student Satisfaction; Student Loyalty; Student Performance

Reference to this paper should be made as follows: Chinomona, E; Macongue, M.B.B. (2021). The effects of loyalty, Satisfaction, and motivation on student's performance: A study of higher education in South Africa, GATR Global J. Bus. Soc. Sci. Review, 9(1): 41 - 49. https://doi.org/10.35609/gjbssr.2021.9.1(5)

\section{Introduction}

With a population of 59 million, South Africa is the 24th-most populous nation in the world. This staggering number of people in South Africa means increased demand of education and therefore the expansion of educational system across the country.

\footnotetext{
* Paper Info: Revised: December 21, 2020

Accepted: March 31, 2021

* Corresponding author: Elizabeth Chinomona

E-mail: elizabethc@vut.ac.za

Affiliation: Vaal University of technology, P Bag X021, 1900, Vanderbijlpark, South Africa
} 
In South Africa, the educational system has re-developed its focus toward helping graduates achieve a global competitiveness necessary to face the challenges of the fourth industrial revolution. Nevertheless, access to education does not automatically result in educational relevance and quality of education. Effectively, Schlesinger, Cervera and Pérez-Cabañero (2016) suggest that the increased enrolment in educational institutions comes with the challenges of improving or maintaining the graduate's rates as well as the performance of the students. Paloș, Maricuţoiu and Coste (2019) noticed that a large number of enrolled students graduate with poor grades, fail to graduate or poorly solve the problems that the South African's society is facing. In an attempt to retain and capture market share with the increase in study options, educational institutions across the country are constantly struggling to provide a distinctive learning experience necessary to improve their students' performance. For instance, Ngoma, Dithan, Ntale and Abaho (2017) attribute the poor performance to the lack of innovative teaching techniques, inadequate materials and the lack of financial support. As a consequence of the deteriorating student performance, the education sector has received serious backlash from a cross-section of South Africa, stressing the need for concerted efforts to address the situation.

According to Lazaro (2020), student performance is described as the extent to which a student achieves their short or long-term goals and objectives. Student performance can be predicted through the application of internal image and external environment, which is also known as Cognitive Learning Theory. Turi, Sorooshian and Javed (2019) found that performance is not only stimuli but also acts on beliefs, thoughts, attitudes, feelings and strives towards goals. Therefore, the quality of the services delivered by higher institution as well as the attitude or believes of the student influence its success or performance. Other studies showed that the ability of a student to learn and succeed is determined by his or her cognitive skills (Williams, Özmen \& McKenna, 2019; Shi, Mi, Li \& Liu, 2019).

This research focuses on higher educational institutions. Lai (2015:119) claims that university students are different as they are expected to be more educated and equipped to deal with a wide range of challenges and advancements than high school or primary students. The results of research by Ridzuan, Yunus, Abdullah, Bakar, Azlan and Ramlan (2018) demonstrates that university students have poor attitude toward classes and subjects. Similarly, Alaslania and Alandejani (2020) showed that university students are more likely to make impulsive decisions such as dropping school as they do not feel any pressure from their peers. In addition, most prior research on performance has been done at high school or colleges, rather than at university level (Organisation for Economic Co-operation and Development (OECD) (2017).

While, studies on student performance in developed countries are well documented, little attention has been dedicated in less developed countries such as South Africa. Given the difference between culture in developed and less developed counties, this study focused on investigating the antecedents of student performance in South African universities.

The purpose of this study is to investigate the factors enhancing student performance of universities in the Gauteng Province. A framework was conceptualized specifically to study the relationship between student loyalty, student satisfaction, student motivation, and student loyalty. In this framework, student loyalty, student satisfaction and student motivation are predictors' variables and student performance is the outcome construct. The figure below shows a framework of the constructs and hypothesised relationships investigated in the study. 


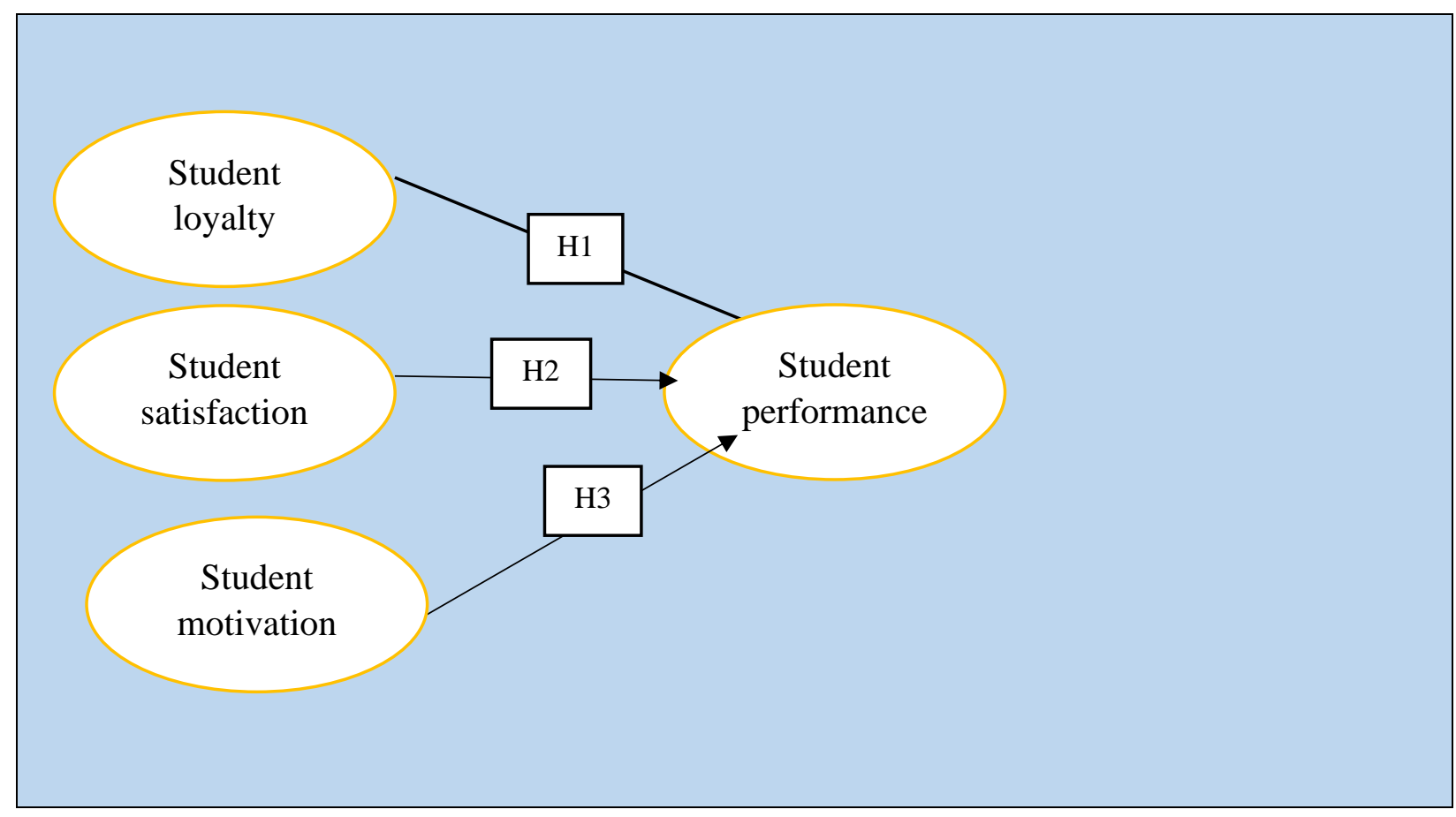

Figure 1. Conceptual Framework and Hypothesised Relationships

\section{Literature review}

The literature review discusses major concepts of this paper which include student loyalty, student motivation, student satisfaction and student performance.

For the purpose of the current discussion and the empirical analysis that follows, student loyalty is regarded as the extent to which a student is committed to a specific educational institution. Loyalty is a critical measure for universities that aim at retaining students until graduation. Generally, loyalty is associated to the degree of assistance the student receives from the institutions which may vary from as small as providing transportation to as large as giving bursaries.

Constantly switching between different institutions can be confusing and result in poor performance. Therefore, Loyalty helps to develop steadiness and consistency needed by students to achieve excellency in their study. Accordingly, Crawford and Derricott (2017) demonstrate that loyal students are more likely to have a positive and favorable perception of their studies and institutions which as a result push them to be actively involved in the co-creation of value for services offered by the education institution and succeed academically. Lim, Jee and De Run (2018), found that loyalty creates a smooth pedagogy environment which promotes the development of an innovative and critical thinking necessary for student to successfully perform in academic learning process. Doña (2018) states the same thing as the studies mentioned earlier that loyalty is one of the most powerful factors that directly or indirectly influence student performance in higher education or universities.

Based on a theoretical study from Crawford and Derricott (2017), Lim, Jee and De Run (2018) and Doña (2018), the following hypotheses can be drawn:

H1: Student loyalty has a significant positive effect on student performance. 
In educational services, satisfaction can be described as a short-term attitude resulting from an evaluation of students' educational experiences and their initial expectations. For students, satisfaction is drawn from institutional traits such as valuable course content, excellent instruction and organised registration. When satisfied, students are psychologically bound with the institutions and its activities.

Student satisfaction is not only a determinant of how much student enjoys their learning experiences, but also how well they perform. Ridzuan et. al., (2018) and Paul and Pradhan (2019) explain in their research that student's grades and course participation with lectures rely on how much they enjoy their time at the university. In the same line, Al-Sheed, Hamouda and Galal (2018) found that satisfied students are more likely to persist in their studies, help lecturers, improve their experience, develop new skills and complete the course work or project successfully. When resources, methods and programs are suitable to the student styles or likeness, subsequently students can engage academically in a successful and productive way.

Based on empirical studies from Ridzuan et. al., (2018), Al-Sheed et. al., (2018) and Paul and Pradhan (2019), the hypothesis below was formulated:

H2: Higher student satisfaction results in higher student performance.

Related to the students' desire to participate in the learning process, motivation is multidimensional theory that can be classified in 3 ways: intrinsic, extrinsic and demotivation. The motivation of a student effect is highly in perception of the university activities, process or programs. The more expectation regarding their study or institutions, the more students are motivated.

Mcgillicuddy and Mcgloin (2018) found that student motivation is a fundamental recipe for academic success. Effectively, when students are properly motivated, a dynamic energy is generated which produces a remarkable impact on their performance. Lindfors, Minkkinen, Rimpelä and Hotulainen (2018) highlight that the motive behind a student selection of a particular course or activities will affect their predisposition, their learning process and their performance. Furthermore, research conducted by Lim et. al. (2018:3) and Parahoo, Santally, Rajabalee and Harvey (2016) shows that competent or excellent students are those are intrinsically motivated to learn, synthesize and connect with diverse materials. In addition, Poon (2018) states that highly motivated students perform better than those who are not, as motivated students have adaptive attitudes and strategies, such as maintaining intrinsic interest, goal setting, and self-monitoring

Based on empirical studies from Lindfors et. al., (2018), Lim et. al. (2018), Parahoo et. al., (2016) and Poon (2018), the following hypothesis is formulated:

H3: Student motivation has a great positive effect on student performance.

\section{Methodology}

The research was conducted in Gauteng University. As a result of the ease of access, geographic closeness and the availability of the respondents, a convenience sampling technique was used to draw respondents relevant to this study. These respondents consisted of university students selected from all departments.

For this study, the quantitative approach was applied as it can be used for large sample which is representative of the population, data can be collected with ease and organised using graph and charts (Shekhar, Prince, Finelli, Demonbrun \& Waters, 2019). Further, this method is suitable since the study involved the testing of six hypotheses suggesting the existence of relationships between four different variables. Data was collected over a period of 8 months (January to August) in 2019 using 3 trained research assistants. Student loyalty was measured using items adopted from Paul and Pradhan (2018), student satisfaction with items adopted from Parahoo, Heather and Tamim (2013), student motivation with measurement items adopted from Nasrin (2018) and student performance with measurement items adopted 
from Ayodele, Oladokun and Oladokun (2017). Response options were presented in 5-point Likert-scales anchored by $1=$ strongly disagree and $5=$ strongly agree to express the degree of agreement or disagreement.

\section{Results}

In this study, two software programs, namely the Statistical Packages for the Social Sciences (SPSS version 25.0) and Analysis of Moment Structures (AMOS 25.0), were used in the data analysis. Simple descriptive statistics were used to analyse the demographic details of respondents while structural equation modelling was used for testing the scale accuracy as well as to test the hypotheses.

\subsection{Descriptive Statistics}

The results show that the majority of the respondents were female compared to male $(n=117 ; 35 \% ; n=218$; $65 \%)$. The age categories of respondents reported were below 21 years $(n=40), 33$ percent were between 21 to 25 years $(n=111), 40$ percent were between 26 and 29 years $(n=134)$ and 15 percent were older than 29 years $(n=50)$. There were more single respondents in the survey, $(n=315 ; 74 \%)$ compared to married respondents $(n=110 ; 26 \%)$. On citizenship of the respondents, South Africans comprised the overall majority of the sample ( $\mathrm{n}=271 ; 81 \%)$, compared to those who were non-South Africans $(\mathrm{n}=64 ; 19 \%)$. The frequencies and percentages of respondent's gender, age group and statute are illustrated in Table 1.

Table 1. Sample demographic characteristics

\begin{tabular}{|c|c|c|}
\hline Gender & Frequency & Percentage \\
\hline Male & 117 & $35 \%$ \\
\hline Female & 218 & $65 \%$ \\
\hline Total & 335 & $100 \%$ \\
\hline Marital status & Frequency & Percentage \\
\hline Married & 103 & $31 \%$ \\
\hline Single & 232 & $69 \%$ \\
\hline Total & 335 & $100 \%$ \\
\hline
\end{tabular}

\begin{tabular}{|c|c|c|}
\hline Age & Frequency & Percentage \\
\hline Below 21 & 40 & $12 \%$ \\
\hline $21-25$ & 111 & $33 \%$ \\
\hline $26-29$ & 134 & $40 \%$ \\
\hline Over 29 & 50 & $15 \%$ \\
\hline Total & 335 & $100 \%$ \\
\hline Citizenship & Frequency & Percentage \\
\hline South Africa & 271 & $81 \%$ \\
\hline Non-South African & 64 & $19 \%$ \\
\hline Total & 335 & $100 \%$ \\
\hline
\end{tabular}

\subsection{Measurement and scale accuracy}

In accordance with the two-step procedure suggested by Anderson and Gerbing (1988), prior to testing the hypotheses, confirmatory factor analysis (CFA) was performed to examine reliability, convergent and discriminant validity of the multi-item construct measures using AMOS 25.0. Overall, acceptable model fit is indicated by goodness-of-fit index (GFI) $\geqq 0.90$; root mean square error of approximation (RMSEA) values $\leqq 0.08$; incremental index of fit (IFI); Tucker Lewis Index (TLI) and comparative fit index (CFI) values $\geqq$ 
0.90. The recommended statistics for the final overall model assessment show acceptable fit of the measurement model to the data: $\chi 2 /(\mathrm{df})=2.411$, GFI $=0.880$; IFI $=0.910$; TLI $=0.904 ;$ CFI $=0.900$; RMSEA $=0.055$. Loadings of individual items on their respective constructs are shown in Table 2, while the scale construct correlations are presented in Table 2.

Table 2. Measurement Accuracy Assessment and Descriptive Statistics

\begin{tabular}{|c|c|c|c|c|c|c|}
\hline \multirow{2}{*}{\multicolumn{2}{|c|}{ Research construct }} & \multirow{2}{*}{\multicolumn{2}{|c|}{ Cronbach's Test }} & \multirow{2}{*}{$\begin{array}{l}\text { C.R. } \\
\text { Value }\end{array}$} & \multirow{2}{*}{$\begin{array}{l}\text { AVE } \\
\text { Value }\end{array}$} & \multirow[t]{2}{*}{ Factors loading } \\
\hline & & & & & & \\
\hline \multirow{5}{*}{$\begin{array}{c}\text { Student } \\
\text { Loyalty (SL) }\end{array}$} & SL1 & $\begin{array}{c}\begin{array}{c}\text { Item- } \\
\text { total }\end{array} \\
0.715 \\
\end{array}$ & \multirow{5}{*}{0.768} & \multirow{5}{*}{0.768} & \multirow{5}{*}{0.609} & 0.770 \\
\hline & SL2 & 0.921 & & & & 0.959 \\
\hline & SL3 & 0.703 & & & & 0.735 \\
\hline & SL4 & 0.635 & & & & 0.702 \\
\hline & SL5 & 0.908 & & & & 0.960 \\
\hline \multirow{5}{*}{$\begin{array}{l}\text { Student } \\
\text { Satisfaction } \\
\text { (SS) }\end{array}$} & SS1 & 0.683 & \multirow{5}{*}{0.700} & \multirow{5}{*}{0.700} & \multirow{5}{*}{0.599} & 0.601 \\
\hline & SS2 & 0.689 & & & & 0.709 \\
\hline & SS3 & 0.833 & & & & 0.882 \\
\hline & SS4 & 0.760 & & & & 0.861 \\
\hline & SS5 & 0.753 & & & & 0.846 \\
\hline \multirow{5}{*}{$\begin{array}{c}\text { Student } \\
\text { Motivation } \\
\text { (SM) }\end{array}$} & SM1 & 0.714 & \multirow{5}{*}{0.791} & \multirow{5}{*}{0.791} & \multirow{5}{*}{0.653} & 0.815 \\
\hline & SM2 & 0.687 & & & & 0.798 \\
\hline & SM3 & 0.693 & & & & 0.785 \\
\hline & SM4 & 0.645 & & & & 0.762 \\
\hline & SM5 & 0.630 & & & & 0.746 \\
\hline \multirow{6}{*}{$\begin{array}{c}\text { Student } \\
\text { Performance } \\
\text { (SP) }\end{array}$} & SP1 & 0.799 & \multirow{6}{*}{0.804} & \multirow{6}{*}{0.804} & \multirow{6}{*}{0.743} & 0.690 \\
\hline & SP2 & 0.656 & & & & 0.698 \\
\hline & SP3 & 0.733 & & & & 0.693 \\
\hline & SP4 & 0.831 & & & & 0.732 \\
\hline & SP5 & 0.922 & & & & 0.824 \\
\hline & SP6 & 0.708 & & & & 0.873 \\
\hline
\end{tabular}

During the cleansing process or the scale purification, item-to-total correlations were computed and were expected to be above the minimum threshold of 0.5 (Hair, Babin, Anderson \& Tatham (2010). Using this criterion, all the items are acceptable as all of them exceed the threshold required. To assess reliability of each construct Cronbach alpha test and the Composite reliability tests were computed. According to Hulland (1999), the recommended minimum value for the two test is supposed to 0.7 in order for measurements scale to be classified as reliable. Table 2 shows that all the measurement scales had Cronbach alpha and composite reliability values above 0.7 ; therefore, it indicating a higher degree of internal reliability and consistency. Furthermore, the inter-construct correlation values are less than the recommended value of 0.6 , revealing an adequate level of discriminant validity (see Table 3).

Table 3. Inter-Construct Correlation Matrix

\begin{tabular}{|c|c|c|c|c|}
\hline Variables & SL & SS & SM & SP \\
\hline SL & 1.000 & & & \\
\hline SS & $.407 * * *$ & 1.000 & & \\
\hline SM & $.400 * * *$ & $.458 * * *$ & 1.000 & 1.000 \\
\hline SP & $.299 * *$ & $.481 * * *$ & $.533 * *$ & \\
\hline \multicolumn{7}{|l}{ Note: SL= Student Loyalty; SS= Student Satisfaction; SM= Student Motivation; SP= Student Performance } \\
\hline
\end{tabular}


An analysis of Table 3 reveals a significant inter-factor correlation ranging between $\mathrm{R}=0.299$ and $\mathrm{r}=0.533$ which all fell within the recommended threshold values. Hence, discriminant validity was considered to be satisfactory in this study since measures (constructs) that were expected to be related were indeed related, as indicated by the correlations constructs of the study.

\subsection{Structural equation modelling}

After approving the reliability and validity of the measurement instruments (reported in Table 2), the study proceeded to test the proposed hypotheses. The study anticipates that student loyalty, satisfaction and motivation have a significant influence on student performance of universities.

Table 4. The Path co-efficient

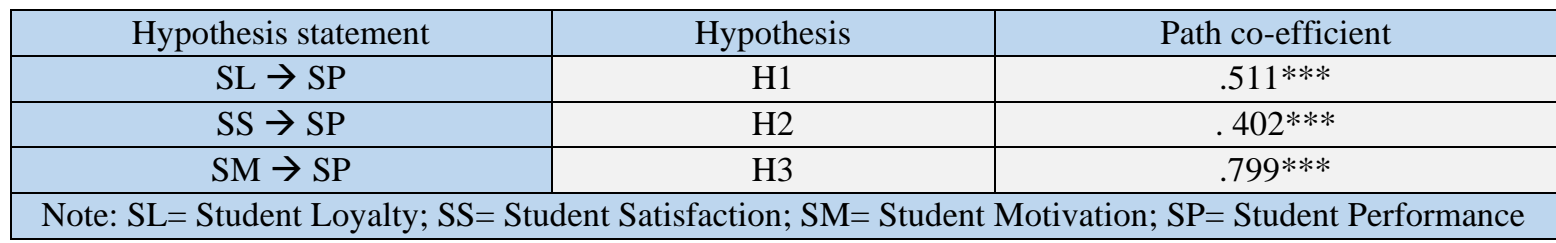

\section{Discussion}

The issue of technology is of concern worldwide especially in the fourth industrial revolution in which students are always on the internet. The results in Table 4, offer support for 3 proposed hypotheses. According to the objectives of the study, it can be deduced that there is a positive relationship between all the 3 hypotheses. The first research objective was to examine the relationship between student loyalty and student performance. Consistent with hypothesis one (H1), the results indicate higher levels of student loyalty and student performance. The path co-efficient is 0.511 , which shows a significant strong relationship. There is, therefore, a significant positive relationship between student loyalty and student performance.

The second research objective was to investigate the relationship between student satisfaction and student performance. Also, in support of hypothesis $2(\mathrm{H} 2)$, the results indicate higher levels of student satisfaction with higher levels of student performance. The results ultimately prove that there is a strong significant positive relationship between student satisfaction and student performance. The path co-efficient of 0.402 shows a strong positive relationship.

The third research objective was to investigate the relationship between student motivation and student performance. The path co-efficient for hypothesis three is 0.799 , which shows a significant relationship between the 2 variables. Of all 3 hypotheses, the strongest relationship was that of student motivation and student performance, which has a standardised coefficient of 0.799 , followed by student loyalty and student performance with a standardised coefficient of 0.511 . The lowest relationship was that of student satisfaction and student performance, which has the lowest standard coefficient of 0.402. Universities not in South Africa only but around the globe need to tighten their belts in improving the student motivation, loyalty and satisfaction to increase the student performance in class.

\section{Conclusions}

The study focused on examining relationships among student loyalty, student motivation and student satisfaction on student performance in universities. The study has both practical and theoretical contributions. Practically, implications of the results are that there is a clear need in higher education for the 
transformation of teaching that is in line with emerging technologies especially in this fourth industrial revolution stage.

Theoretically, it provides added literature on student motivation, student satisfaction, student loyalty and student performance. The research model, which is robust and one of a kind makes the study more interesting and contributes to new knowledge. However, on the practical side, the educators need to adopt measures and improvements on student motivation, satisfaction and loyalty to improve student performance.

The study used a quantitative research design, although future research may consider adopting a qualitative approach or mixed method approach to get more meaningful results. A larger sample can be considered in order to generalize findings. Panezai (2019) indicates that "there is need of a larger sample to make the findings more generalizable". However, the present research can be seen as a preliminary investigation of the opportunity to increase value in improving student motivation, satisfaction and loyalty in South Africa and other countries.

\section{References}

Al-Sheeb, B., Hamouda, A. M., \& Abdella, G. M. (2018). Investigating determinants of student satisfaction in the first year of college in a public university in the state of Qatar. Education Research International, 2018.https://doi.org/10.1155/2018/7194106

Ayodele, T. O., Oladokun, T. T., \& Oladokun, S. O. (2017). Factors influencing real estate students' academic performance in an emerging economy. Property Management.htpps://doi.org://10.1108/PM-08-2016-0041

Crawford, K. \& Derricott, D. 2017. Developing Student Engagement in Higher Education. Lincoln, UK: SAGE Publishing.

Doña Toledo, L., \& Luque Martínez, T. (2020). How loyal can a graduate ever be? The influence of motivation and employment on student loyalty. Studies in Higher Education, 45(2), 353-374. https://doi.org/10.1080/03075079.2018.1532987

Hair, J.F., Babin, B.J., Anderson, R.E. \& Tatham, R.L. 2010. Multivariate Data Analysis. A global perspective. 7th ed. London: Prentice-Hall.

Hulland, J. (1999). Use of partial least squares (PLS) in strategic management research: A review of four recent studies. Strategic management journal, 20(2), 195-204. https://doi.org/10.1002/(SICI)1097-0266(199902)20:2<195::AIDSMJ13>3.0.CO;2-7

Lai, I. K. (2015). The roles of value, satisfaction, and commitment in the effect of service quality on customer loyalty in Hong Kong-style tea restaurants. Cornell Hospitality Quarterly, 56(1), 118-138.htpps://doi.org.:// $10.1177 / 1938965514556149$

Lim, W. M., Jee, T. W., \& De Run, E. C. (2020). Strategic brand management for higher education institutions with graduate degree programs: empirical insights from the higher education marketing mix. Journal of Strategic Marketing, 28(3), 225-245. https://doi.org/10.1080/0965254X.2018.1496131

Lindfors, P., Minkkinen, J., Rimpelä, A., \& Hotulainen, R. (2018). Family and school social capital, school burnout and academic achievement: a multilevel longitudinal analysis among Finnish pupils. InternatIonal Journal of adolescence and Youth, 23(3), 368-381. https://doi.org/10.1080/02673843.2017.1389758

McGillicuddy, K. T., \& McGloin, R. (2018). 'Should I use it?'Assessing the value of online supplemental course materials and their influence on student performance. Technology, Pedagogy and Education, 27(3), 327-337. https://doi.org/10.1080/1475939X.2018.1448298

Nasrin, S. (2018). Investigating Students Motivation towards Learning and Factors Influencing Behind: A Primary Data Analysis. International Journal of Asian Social Science, 8(12), 1139-1146. htpps://doi,org/ 10.18488/journal.1.2018.812.1139.1146

Ngoma, M., Ntale, P. D., \& Abaho, E. (2017). Social-economic factors, student factors, student academic goals and performance of students in institutions of higher learning in Uganda. Africa Education Review, 14(2), 106-121. https://doi.org/10.1080/18146627.2017.1286941

Organisation for Economic Co-Operation and Development (OECD). 2017. PISA 2015 results

(Volume III): Students' well-being. Paris: OECD Publishing. https://www.oecd.org/pisa/PISA-2015-Results-StudentsWell-being-Volume-III-Overview.pdf 
Paloș, R., Maricuţoiu, L. P., \& Costea, I. (2019). Relations between academic performance, student engagement and student burnout: A cross-lagged analysis of a two-wave study. Studies in Educational Evaluation, 60, $199-204$. htpps://doi.org:/ 10.1016/j.stueduc.2019.01.005.

Panezai, S. 2019. The Advantages of a Large Sample Size. [Online]. Available at: https://sciencing.com/advantageslarge-sample-size-7210190.html. Accessed 27 January 2021.

Parahoo, S. K., Harvey, H. L., \& Tamim, R. M. (2013). Factors influencing student satisfaction in universities in the Gulf region: does gender of students matter?. Journal of Marketing for Higher Education, 23(2), 135154.https://doi.org:/ 10.1080/08841241. 2013.860940

Paul, R., \& Pradhan, S. (2019). Achieving student satisfaction and student loyalty in higher education: A focus on service value dimensions. Services Marketing Quarterly, 40(3), 245268.https://doi.org/10.1080/15332969.2019.1630177.

Poon, J. 2018. Postgraduate student satisfaction in the UK. Property Management, 7-22. https://doi.org./10.1108/PM07-2017-0041

Ridzuan, A. R., Yunus, M. K., Abdullah, M. H., Bakar, M. H., Azlan, N. A., \& Ramlan, A. F. (2018). The Relationship between Students' Satisfaction and their Academic Performance among Public Relations Degree Students in UiTM Alor Gajah Melaka. International Journal of Academic Research in Business \& Social Sciences, 8(10), 874882.https://doi.org./ 10.6007/IJARBSS/v8-i10/4785

Shekhar, P., Prince, M., Finelli, C., Demonbrun, M., \& Waters, C. (2019). Integrating quantitative and qualitative research methods to examine student resistance to active learning. European Journal of Engineering Education, 44(1-2), 6-18. https://doi.org/10.1080/03043797.2018.1438988

Shi, Y., Mi, Y., Li, J., \& Liu, W. (2019). Concurrent concept-cognitive learning model for classification. Information Sciences, 496, 65-81. https://doi.org/10.1016/j.ins.2019.05.009 